\title{
A EDUCAÇÃO DO CORPO NA FORMAÇÃO DE PROFESSORES NA ESCOLA NORMAL PAULISTA (1890-1931)
}

\author{
Tony Honorato ${ }^{1}$ \\ Ana Clara Bortoleto Nery ${ }^{2}$
}

RESUMO: A Escola Normal Paulista foi lócus de promoção de inovaçôes pedagógicas e de irradiação de saberes e práticas ao magistério primário. As práticas corporais de cultivo físico e estético, produtoras de uma educação do corpo, eram aquelas que os reformadores e os agentes da instrução pública tinham o interesse de difusão para ter um impacto sobre as Escolas Primárias, foco da regeneração social. Então, quais práticas que compuseram um sentido de educação do corpo estavam presentes na formação de normalistas (1890-1931)? Como resultado, centramos análises sobre a Ginástica e o Escotismo.

Palavras-chave: Educação do corpo. Ginástica. Escotismo. Escola Normal. Impresso pedagógico.

\footnotetext{
${ }^{1}$ Universidade Estadual de Londrina, Departamento de Educação Física Londrina (PR), Brasil. E-mail: tonyhonoratu@gmail.com

${ }^{2}$ Universidade Estadual Paulista "Júlio de Mesquita Filho", Faculdade de Filosofia e Ciências - Marília (SP), Brasil. E-mail: neryanaclara@gmail.com DOI: $10.1590 / C C 0101-32622018178522$
} 


\title{
The education of the body in teachers' training in Normal School of the state of Sáo Paulo (1890-1931)
}

\begin{abstract}
In the state of São Paulo, Brazil, the Normal School was responsible to spread pedagogic innovations and diffuse new knowledge and practices for primary school. We assume that physic and aesthetic corporal practices, producers of a body education and offered in Normal School, were those reformers and public institution officials who broadcast interest in having an impact grade schools, focusing on social regeneration. So, which practices composed a sense of this education of the body in teacher's training (1890-1931)? As a result, we focused the analyses on gymnastics and scouting.
\end{abstract}

Keywords: Education of the body. Gymnastic. Scouting. Normal School. Pedagogical printed.

\section{INTRODUÇÃO}

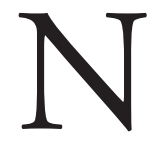

o Estado de São Paulo, a Escola Normal ${ }^{1}$ foi uma instituição modelar para formar professores entre o século XIX e as primeiras décadas do século XX. Era incumbida de preparar profissionais doutos em modernas pedagogias destinadas ao ensino elementar, os quais nas Escolas Primárias seriam representantes do reordenamento social idealizado pelos republicanos. A Escola Normal deveria irradiar as inovaçóes pedagógicas, o combate ao analfabetismo, os novos modos de trabalho livre, os valores políticos eleitorais, as ideologias nacionalistas e os bons costumes voltados ao cultivo da saúde do corpo social.

Um dos propósitos dessa instituição modelar ${ }^{2}$ era a educação integral do homem - intelectual, física e moral —, permitindo colocar em evolução e hierarquia o conhecimento e a vida social na perspectiva das ciências, especialmente a positivista, espraiando-se gradualmente para outras perspectivas. Ao empreender a educação integral, na formação de normalistas fundava-se, também, um tipo de educação do corpo cuja proposição, a partir da educação dos sentidos 
físicos e estéticos, consistia em levar os indivíduos, em fase escolar, a comportarem-se de maneira mais polida, saudável e civilizada ${ }^{3}$ em sociedade. Erigir-se-ia, assim, o futuro da nação!

Considerando a função da Escola Normal de colaborar para a regeneração da vida social, propusemos um estudo sobre a educação do corpo na formação de professores. Partimos da premissa de que as práticas corporais de cultivo físico e estético, produtoras de uma educação do corpo e ofertadas no âmbito da Escola Normal, eram aquelas que os reformadores e os agentes da instrução pública tinham o interesse de difusão para ter um impacto sobre as Escolas Primárias, foco da regeneração social.

Nesse sentido, o objetivo do estudo foi identificar quais práticas compuseram um sentido de educação do corpo presente na formação de normalistas. Para tanto, as fontes históricas eleitas foram os textos das reformas educacionais do período, das revistas pedagógicas (Revista de Ensino 1902-1918; Revista Escolar 1925-1927; Educação 1928-1930; Escola Nova 1930) e dos programas de ensino para as Escolas Normais propostos, subsidiados e divulgados pelos órgãos de administração da instrução pública, no período entre 1890 e 1931. O recorte justifica-se em razão de a Reforma "Caetano de Campos”, de 1890, passando por outras várias reformas, até a Reforma "Lourenço Filho", de 1930, representarem um tempo em que as práticas corporais (Ginástica, exercícios militares, Escotismo, jogos, exercícios de cantos, orientaçôes higiênicas e sanitárias) foram oficialmente instituídas e potencializadas processualmente até a criação do Departamento de Educação Física da Diretoria Geral de Ensino do Estado de São Paulo, em 1931.

\section{FORMANDO PROFESSORES SAUDÁVEIS PARA FORMAR CRIANÇAS SAUDÁVEIS: A GYMNASTICA}

Com a Reforma "Caetano de Campos" se institucionaliza o método intuitivo na Escola Normal da Capital e se erige o modelo escolar paulista, conforme Carvalho (2011). Os modelos de boas práticas eram desenvolvidos na Escola Normal para que chegassem 
até as Escolas Primárias, onde o futuro cidadão republicano era forjado. A formação de professores, nessa Escola Normal e nas demais congêneres, visava à formação intelectual, moral e física das crianças. Ao analisarmos as fontes empíricas, uma série de atividades, práticas e conceitos sobre o corpo emergiu. A educação do corpo não estava circunscrita a uma matéria ou atividade específica, e sim a um conjunto de saberes e práticas corporais curriculares (Ginástica, Música, Noções de Higiene, Trabalhos Manuais, Economia Doméstica, Desenho) e até mesmo nas atividades não previstas nos programas de ensino, como é o caso do Escotismo, que adentrará as Escolas Normais e as Escolas Primárias na transição dos anos de 1910 para os de 1920. Não será possível, aqui, trabalhar todos os elementos da educação do corpo desenvolvidos juntos aos normalistas. Focaremos mais especificamente na Gymnastica, enquanto aula prevista nos programas de ensino das Escolas Normais e das Escolas Complementares, e no Escotismo, enquanto formaçáo complementar, amplamente disseminado no aparelho escolar paulista.

A inclusão da Gymnastica no programa de ensino da Escola Normal da Capital não ocorreu de forma homogênea para as seçóes masculina e feminina. Em 1890, a Reforma "Caetano de Campos" estabelecera exercícios militares para os homens, bem como exercícios gymnasticos e manuais apropriados aos sexos. A educação do corpo masculino seguiria rumo à força, à harmonia e à "marcha"; já a do corpo feminino, rumo à estética do movimento, aos ritmos espontâneos e aos exercícios físicos, sem colocar em risco a condição de mulheres geradoras dos filhos da pátria que, a despeito, praticavam aulas de prendas enquanto os meninos realizavam exercícios militares. A Gymnastica era introduzida apenas no segundo ano da formação, com duas aulas semanais, e havia um professor para a seção masculina e uma professora para a seção feminina (SÃO PAULO, 1890).

Nas Escolas Complementares, que passaram a formar professores para a Escola Primária a partir de 1896, haviam, segundo o Regimento Interno (SÃO PAULO, 1896), Exercícios Gymnasticos ministrados pelos professores das matérias do programa ou por um mestre contratado e designado pelo diretor do estabelecimento. A partir de 1911 — com as mudanças efetuadas nas escolas de forma- 
ção de professores —, a contratação de um professor específico para a Gymnastica passa a ser exigida pela legislação (SÃO PAULO, 1911). Em 1912, a Escola Normal Primária de Piracicaba, localizada no interior paulista, contratou David Müller para a seção masculina de Ginástica; em 1917, contratou, para a seção feminina, Olívia Bianco (FAUSTINO, 1919).

Conforme a profa Olívia Bianco (1921, p. 110), "é da esfera da Educação Física, hoje arte de objetivos conscientes e já muito distanciada do empirismo, encaminhar o ser humano para a sua perfeita organização somática, como a intelectual e moral preparam as qualidades de espírito e de caráter". Pela educação do corpo seria possível atingir graduaçóes físicas e morais que elevariam o homem à condição de evoluído e superior; para tanto, os exercícios gímnicos racionais e cientificamente sistematizados seriam os meios propícios para a formação de um tipo ideal de homem integral e saudável.

O diretor Honorato Faustino, da Escola onde Bianco lecionara, relata:

A par do desenvolvimento intelectual, moral e cívico dos alunos, náo nos temos descuidado da sua Educação Física. É assim que temos procurado desenvolver aqui uma ginástica racional e apropriada ao desenvolvimento harmônico das diversas partes do corpo ao mesmo tempo dando largo incremento aos diversos jogos escolares, cuidadosamente escolhidos, a fim de que possam não só despertar interesse como atingir o objetivo visado (FAUSTINO, 1919, p. 21).

[...] não temos descuidado tudo quanto se refere à educação dos sentidos e a correção não só de seus erros fisicamente fisiológicos, como de seus desvios patológicos, na medida dos elementos de que podemos dispor. Completando essa parte, temos procurado generalizar certas noçóes de higiene, pondo-as ao alcance da inteligência de crianças, de modo a habituá-las a saberem evitar alteração da saúde (FAUSTINO, 1921, p. 9). 
A Educação Física não era considerada um componente curricular, como o é na atualidade, e sim um conceito mais amplo, perpassando diferentes saberes e práticas; por isso a formação de professores tinha o objetivo de estimular comportamentos educados rumo ao cultivo do corpo saudável, higiênico, harmônico e disciplinado, caso contrário prejudicaria o desenvolvimento intelectual e a inteireza do indivíduo. Para tanto, segundo Honorato (2015), além da contratação de professores específicos, as Escolas Normais deveriam ser equipadas com aparelhos adequados para as aulas de Gymnastica, bem como dispor de espaços específicos, como ginásios, e garantir o tempo escolar da educação do corpo como recurso formativo do futuro professor a educar crianças saudáveis.

Em 1912, o Programa de Ensino para as Escolas Normais demonstra que as relaçóes entre as cadeiras e as aulas permaneciam as mesmas do período anterior: a Gymnastica obtinha o status de aula, e não o de cadeira, uma espécie de protodisciplina, na perspectiva de Viñao (2008).

No entanto, com a Reforma “Oscar Thompson”, em 1911, as aulas de Gymnastica estavam presentes nas Escolas Normais primárias e secundárias (Quadro 1). Embora nas secundárias o mestre recebesse maiores vencimentos do que nas primárias, o seu salário era inferior ao dos lentes catedráticos. No geral, por meio de jogos infantis, passeios, noçóes de hygiene e gymnastica educativa, essas instituiçóes formavam os professorandos em diferenciadas seçóes: masculina e feminina.

\section{Quadro 1}

Número de aulas de Gymnastica (1912).

\begin{tabular}{|l|c|c|c|c|}
\hline \multicolumn{2}{|c|}{ Lei } & Gymnastica & Responsável & Vencimentos \\
\hline $\begin{array}{l}\text { Decreto } \\
n^{\circ} .2 .025\end{array}$ & $\begin{array}{c}\text { Escola } \\
\text { Pormal } \\
\text { Primária }\end{array}$ & $\begin{array}{c}2 \text { aulas semanais } \\
\text { do } 1^{\circ} \text { ao } 4^{\circ} \text { ano }\end{array}$ & $\begin{array}{c}\text { Mestre } \\
\text { contratado }\end{array}$ & $\begin{array}{c}3: 200 \$ 000(60 \% \\
\text { do vencimento } \\
\text { do catedrático })\end{array}$ \\
\hline $\begin{array}{l}\text { Decreto } \\
n^{\circ} .2 .367\end{array}$ & $\begin{array}{c}\text { Escola } \\
\text { Normal }\end{array}$ & $\begin{array}{c}3 \text { aulas semanais } \\
\text { no } 1^{\circ} \text { ano e } 2 \\
\text { aulas no } 2^{\circ} \text { ao } \\
4^{\circ} \text { ano }\end{array}$ & $\begin{array}{c}\text { Mestre } \\
\text { contratado }\end{array}$ & $\begin{array}{c}4: 800 \$ 000(80 \% \\
\text { do vencimento } \\
\text { do catedrático })\end{array}$ \\
\hline
\end{tabular}

Fonte: São Paulo (1911; 1913). 
Com as reformas, os programas de ensino e o artigo de Bianco, percebemos uma gradual mudança na concepção de Educação Física: procurava-se substituir a clássica coleção de exercícios musculares fastidiosos que não despertavam interesse e até mesmo eram prejudiciais aos alunos.

No mesmo sentido, as palavras do Inspetor Especial de Educação Física da Diretoria Geral de Instrução Pública de São Paulo, prof. Augusto Ribeiro de Carvalho (1929, p. 302), publicadas no periódico Educação, orientam: "a criança deve ir a uma aula de Gymnastica como quem vai a uma festa e não a um enterro, a um ato fúnebre. Por isso, deve sempre o professor preparar ou predispor os ânimos para essas aulas, em que se faz a festa do músculo, a festa da saúde". Como ilustração, o artigo do inspetor, intitulado "Educação Physica”, apresenta uma imagem de alunas da Escola Normal de São Carlos, interior paulista, executando um bailado de base calistênica, sob a orientação da profa D. Elsa Abbt, conforme Figura 1.

\section{Figura 1}

Normalistas em formação gímnica.

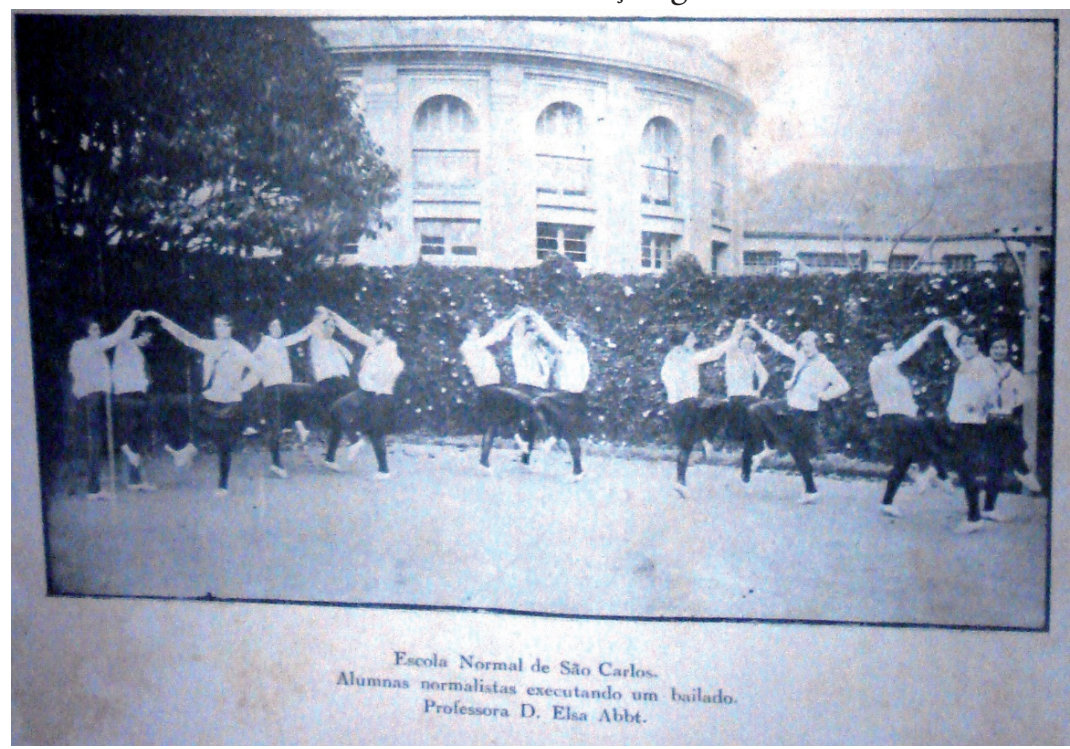

Fonte: Carvalho (1929). 
Além da calistenia, o inspetor prof. Augusto Ribeiro de Carvalho orientava, por meio de liçôes, que a progressão de exercícios gímnicos útil ao desenvolvimento do corpo deveria seguir o método racional e científico de Gymnastica Sueca preconizado por Pehr Henrik Ling. Com efeito, no ensino normalista inseriam-se cada vez mais os princípios da Educação Física moderna com base nas ginásticas sueca, francesa e calistênica, bem como nos jogos escolares, para então desenvolver harmonicamente os músculos, os órgãos e as energias vitais, além de fortalecer as forças internas para se relacionarem com o mundo exterior.

Depois de abordar a presença da Gymnastica e de outras práticas como um elemento da educação do corpo no processo de formaçáo de professores, pergunta-se: como estava a realidade do ensino de Gymnastica nas Escolas Primárias do Estado de São Paulo?

Com a Reforma "Lourenço Filho", fora criado o Departamento de Educação Física da Diretoria Geral de Ensino de São Paulo, em 1931. Com o propósito de saber o alcance da Gymnastica no ensino primário, elaborou-se um inquérito sobre as Condiçóes do Ensino da Gymnastica nos Grupos Escolares da Capital, publicado em 1932, no periódico Educação. O documento consistia em uma síntese das informaçóes coletadas junto aos diretores de 51 grupos que responderam a um questionário (RIBEIRO; DETTHORO, 1932).

A realidade extraída dos grupos escolares da capital indica que o ensino da Gymnastica ainda enfrentava dificuldades de oferta; isso dizia respeito também à necessidade de formação de professores com expertise na matéria em pauta. Demanda essa inicialmente atendida com a inauguração, em 1934, da Escola Superior de Educação Physica do Estado de São Paulo (ESEP), de natureza civil.

O fato é que, até o início dos anos de 1930, o ensino da Gymnastica nem sempre se efetivou plenamente nas Escolas Primárias, em razão das condiçóes objetivas e materiais e da ausência de especialistas em matéria de exercícios para meninos e para meninas. Em concomitância, o que se vê também é a introdução de diferentes práticas e saberes voltados à educação do corpo nas Escolas Normais, 
particularmente o Escotismo, conteúdo que ficara também sob a responsabilidade do professor no ensino primário.

\section{NACIONALISMO E DESENVOLVIMENTO INTEGRAL: O ESCOTISMO ESCOLAR}

O movimento escoteiro foi iniciado nas escolas públicas paulistas em 1917, quando foi implantado o curso, ministrado por Dr. Mário Cardim e Coronel Pedro Dias de Campos, para diretores e inspetores escolares (NERY, 2009, p. 145). O Escotismo foi oficializado com a Reforma de 1920, tornando-se atividade facultativa à educação do corpo. Nesse momento ele passa a ser prática frequente nas Escolas Normais, para que os normalistas pudessem ser os instrutores do Escotismo enquanto professores das Escolas Primárias. A reforma previa a adoção do Escotismo nas escolas públicas, acompanhado das linhas de tiro (SÃO PAULO, 1921).

Os alunos das escolas públicas eram aspirantes a escoteiro e o encargo de administrar as atividades era, geralmente, dos professores de Gymnastica. Os relatórios dos inspetores escolares da Diretoria Geral da Instrução Pública de São Paulo trazem diversas notícias sobre as atividades escoteiras. No ano de 1923, o diretor-geral Guilherme Kuhlmann evidencia sua opiniáo:

O escotismo implantou-se de vez nas escolas paulistas e seus frutos têm sido magníficos. Mas fizemos um escotismo nosso, de acordo com o nosso meio, adaptado às nossas condiçóes de vida. Ligamo-lo às tradiçôes da nossa história, dando a cada comissão regional o nome de um bandeirante. Teve assim o Governo de S. Paulo o intuito louvável e muito patriótico de reviver as glórias do nosso passado (ANUÁRIO DE ENSINO, 1923, p. 29-30).

No mesmo Anuário, cada delegado regional faz o relatório da sua área, quase todos citam as atividades escoteiras. Em um desses 
registros, o inspetor regional afirma que a atividade colaborava para o "desenvolvimento do espírito de iniciativa, da coragem, da decisáo, da disciplina moral e do civismo" e "de acordo com os altos interesses nacionais". Transparece um grande entusiasmo nos relatos dos delegados sobre as atividades escoteiras. Não há dúvidas de que o Escotismo tenha provocado um novo ânimo nos alunos das escolas públicas; para comprová-lo, basta termos em mente que havia, em 1923, por volta de 100.000 escoteiros escolares. Segundo um dos delegados, o "Decreto 3.531, de 22 de novembro de 1922, reintegrou o professor em seu verdadeiro lugar, dando-lhe a direção do escotismo, sociedade em que a ele pertence e que a ela estava sendo usurpada" (ANUÁRIO DE ENSINO, 1923, p. 93-111). Para o autor desse relatório, cabia aos professores das escolas a orientação sobre o Escotismo, apesar de a atividade ter sido instituída junto às linhas de tiro, o que poderia caracterizá-la como militarista.

Fica claro, ainda, no trecho que se segue, o propósito com que se realizavam as atividades escoteiras.

Ao professor paulista, particularmente, o caminho é apontado pelo sopro de vida que anima todos os recantos do Estado pela massa de estrangeiros que colabora conosco e que precisa ser integrada no nosso país; pela população que cresce assombrosamente e cidades que surgem por encanto; pelo exemplo heróico dos nossos antepassados e pela responsabilidade de São Paulo como guia e condutor da vida e do progresso do Brasil (ANUÁRIO DE ENSINO, 1923, p. 112).

O Escotismo tinha por finalidade nacionalizar a grande massa de estrangeiros que habitava o Estado de São Paulo; mais do que nacionalizar, a proposta era de regeneraçáo da raça. Em relação às atividades, os relatórios informam que os escoteiros desenvolviam exercícios variados e excursóes diversas e as aulas eram ministradas na escola, no período das atividades de Educação Cívica e Moral, ou fora do horário escolar - em ambos os casos, por professores entusiastas do Escotismo. Todos esses elementos expóem a importância que o Es- 
cotismo havia tomado e a necessidade de desenvolvimento da prática nas Escolas Normais.

A Revista Escolar, meio de comunicação da Diretoria Geral da Instrução Pública com os professores, publicada após a Reforma de 1925, veicula o maior número de informações sobre o Escotismo Escolar. Basta verificar que já no primeiro número do mensário, publicado em janeiro de 1925, há um artigo em que o autor defende a prática do Escotismo nas escolas, com benefícios cívicos e morais, apoiada pelos pais e desenvolvida pelos educadores. O periódico dános noçôes de como era a prática, entre 1925 e 1927, do Escotismo nas escolas. O tema aparece em 22 artigos da revista e há várias músicas cantadas por escoteiros, além de algumas fotografias - nas quais se observa que a prática nas escolas seguia os padróes da Associaçáo Brasileira dos Escoteiros. O periódico é notável na defesa do Escotismo orientado pelos professores.

Os professores devem cultivá-lo com carinho e patriotismo, de acordo com os princípios e programas do General Baden-Powell, adaptando-os, porém, tanto quanto possível, às condiçóes da vida nacional. O escotismo é uma escola de regeneração, na decadência a que pode ser levada a sociedade; é a escola do Bandeirante, que reage contra a degeneração da nação (REVISTA ESCOLAR, 1925-1927, p. 96).

Um dos artigos descreve que, além da formação cívica, moral e intelectual, o Escotismo trabalhava a educação do corpo integralmente. Além da formação cívica, moral e intelectual, tal atividade se ocupava do desenvolvimento do corpo.

As excursões, os trabalhos de acampamento, a gymnastica, os diferentes desportos ao ar livre e outros exercicios peculiares ao escotismo, desenvolvem os músculos, revigoram o corpo, regularizam as funcçôes vitaes, robustecem, enfim, dum modo geral, a saúde. [...] 
Assim considerado, o escotismo é a verdadeira escola que prepara o cidadão de amanhã - o corpo varonil, a alma generosa, a inteligência lucida para bem servir ao seu paiz (REVISTA ESCOLAR, 1925-1927, p. 44).

No último número da Revista Escolar, em 1927, há um artigo que discute, pela primeira vez, o Escotismo Feminino, como uma prática que já era desenvolvida, porém pouco aceita pelas meninas. Aponta a finalidade desse movimento considerando que "seria ele uma das condiçóes primeiras no preparo e adestramento da mulher para a missão social que lhe é imposta”.

A Figura 2 ilustra que as atividades corpóreas desenvolvidas na Escola Normal de Piracicaba haviam adquirido grande importância. Por ocasião das comemoraçóes do Centenário da Independência do Brasil, o diretor Honorato Faustino organizou uma festa que expôs à cidade os trabalhos desenvolvidos na escola. Na Figura 2 vemos, além da demonstraçáo de gymnastica feminina, um grupo grande de escoteiros, na frente da instituição, a demonstrar algumas das formaçóes.

Na Escola Normal de Piracicaba e anexas, militares e civis ministravam atividades aos escoteiros, assim como o prof. David Müller instruía o exercício físico e o diretor Honorato Faustino orientava as questóes morais e cívicas presentes no Código dos Escoteiros e ainda transmitia noçóes científicas e práticas concernentes ao Escotismo.

Assim, o espírito cívico compunha também a educação do corpo, por isso deveria ser objeto da Escola Primária para além dos programas de ensino e de atenção toda particular por parte dos cursos de formaçáo de normalistas. Posto que a partir do trabalho do futuro professor esperava-se melhorar as futuras geraçóes, aperfeiçoar as condutas patriotas dos alunos. Logo, o professor deveria encaminhar o ensino almejando inculcar costumes e hábitos ancorados na educação para desenvolver o patriotismo cívico, a energia compreendendo a saúde, o caráter potencializando a coragem e a honra, a inteligência voltada à iniciativa, à observação e à logicida- 


\section{Figura 2}

Comemoração do Centenário da Independência na Escola Normal de Piracicaba (1922).

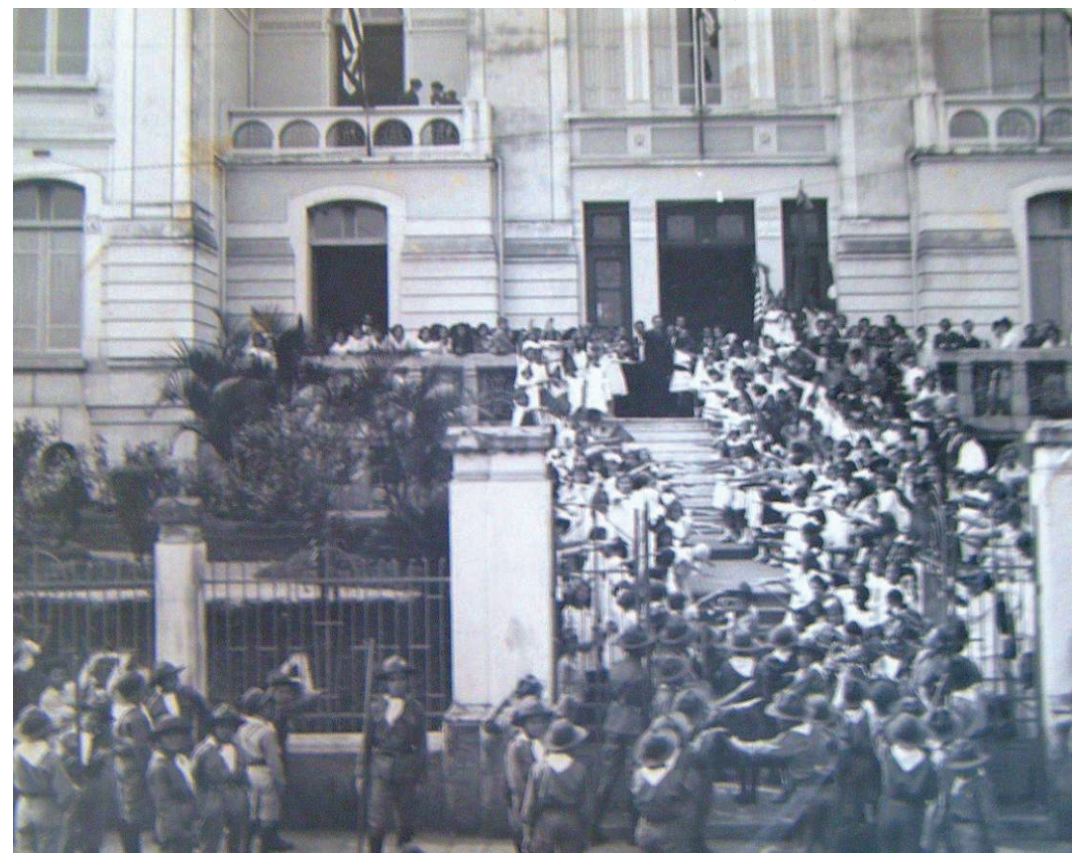

Fonte: Acervo iconográfico da Escola Normal de Piracicaba.

de, bem como o espírito prático destinado aos socorros de urgência e às atividades manuais. Portanto, ao professor caberia desenvolver o seu nobre papel de incrementar o Escotismo entre os alunos, por isso ele deveria conhecer e se apropriar de princípios da educação do corpo relacionados à prática.

\section{CONSIDERAÇÕES FINAIS}

O estudo identificou as práticas da educação do corpo desenvolvidas na formação de normalistas paulistas (1890-1931), as influências e as orientaçóes, bem como as formas pelas quais o futu- 
ro professor ensinaria a Gymnastica e o Escotismo aos seus futuros alunos, uma vez que, em muitas Escolas Primárias, a unidocência era efetivada.

Por fim, enquanto os programas de ensino dão as balizas sobre o que ensinar, a imprensa pedagógica analisada apresenta modelos, discussóes e práticas de uso do corpo na regeneração social, demonstrando as diferenças das atividades voltadas para cada um dos sexos.

\section{REFERÊNCIAS}

ANUÁRIO DE ENSINO. Diretoria Geral de Instrução Pública. 1923.

BIANCO, O. Educação Physica. Revista de Educação, Piracicaba, v. 1, n. 1, p. 110-112, maio 1921.

CARVAlHO, A.R. Educação Physica. Educaçâo. Órgão da Diretoria Geral do Ensino de São Paulo, n. 3, v. 7, p. 302-306, jun. 1929.

CARVAlHO, M.M.C. Pedagogia Moderna, Pedagogia da Escola Nova e Modelo Escolar Paulista. In: CARVALHO, M.M.C.; PINTASSILGO, J. (Orgs.). Modelos culturais, saberes pedagógicos, instituiçóes educacionais. Sáo Paulo: EDUSP, 2011. p. 187-216.

ELIAS, N. O processo civilizador: uma história dos costumes. Rio de Janeiro: Jorge Zahar, 1994. v. 1.

FAUSTINO, H. Relatório da Diretoria da Escola Normal Primária de Piracicaba. Arquivo Permanente da Escola Estadual "Sud Mennucci de Piracicaba". Piracicaba, 1919.

Relatório da Diretoria da Escola Normal de Piracicaba. Arquivo Permanente da Escola Estadual "Sud Mennucci de Piracicaba". Piracicaba, 1921. GÓIS JÚNIOR, E.; BATISTA, J.C.F. A introdução da Gymnastica na Escola Normal de São Paulo (1890-1908). Movimento, Porto Alegre, v. 16, n. 3, p. 71-87, jul./set. 2010.

HONORATO, T. A Educação Física na formação de professores normalistas (1897-1921). Movimento, Porto Alegre, v. 21, n. 3, p. 743757, jul./set. 2015. 
MORENO, A.; SEGANTINI, V.C.; FERNANDES, G.A.; JESUS, L.J. "Gesticulação nobre, sympathica e attitude digna": educaçáo do corpo na formação de professoras (Escola Normal Modelo da Capital, Belo Horizonte, 1906-1930). Revista Brasileira de História da Educação, Campinas, v. 12, n. 1 (28), p. 221-242, jan./abr. 2012.

NERY, A.C.B. A Sociedade de Educação de São Paulo. São Paulo: Editora da Unesp, 2009.

REVISTA ESCOLAR. Diretoria Geral da Instrução Pública. São Paulo: Typografia do Estado, 1925-1927.

RIBEIRO, B.A.; DETTHORO, F. Inquérito sobre as Condições do Ensino da Gymnastica nos Grupos Escolares. Educação. Órgão da Diretoria Geral do Ensino de São Paulo, v. 7, n. 4-5, p. 82-87, abr./maio 1932.

SÃO PAULO. Decreto no 27, de 12 de março de 1890. Reforma a Escola Normal e converte em escolas modelos as escolas anexas. São Paulo, 1890. Disponível em: <http://www.al.sp.gov.br/norma/?id=137755>. Acesso em: 22 ago. 2017.

- Decreto no 400, de 6 de novembro de 1896. Aprova o Regimento Interno das Escolas Complementares do Estado. Sáo Paulo, 1896. Disponível em: shttp://www.al.sp.gov.br/norma/?id=137273>. Acesso em: 22 ago. 2017.

SÃO PAULO. Decreto no 2.025, de 29 de março de 1911. Converte as atuais Escolas Complementares do Estado em Escolas Normais Primárias e dá-lhes regulamento. São Paulo, 1911. Disponível em: <http://www.al.sp.gov.br/ norma/?id=135390>. Acesso em: 22 ago. 2017.

. Decreto no 2.367, de 14 de abril de 1913. Aprova o Regulamento das Escolas Normais de curso secundário e escolas anexas. São Paulo, 1913. Disponível em: <http://www.al.sp.gov.br/norma/?id=135084>. Acesso em: 22 ago. 2017.

. Decreto no 3.356, de 31 de maio de 1921. Regulamenta a Lei no 1.750 , de 8 de dezembro de 1920, que reforma a instrução pública. Sáo Paulo, 1920. Disponível em: shttp://www.al.sp.gov.br/norma/?id=133890>. Acesso em: 22 ago. 2017.

VAGO, T.M. Cultura escolar, cultivo de corpos: educação physica e gymnastica como práticas constitutivas dos corpos de crianças no ensino público primário de Belo Horizonte (1906-1920). Bragança Paulista: UDUSF, 2002.

VIÑAO, A. A história das disciplinas escolares. Revista Brasileira de História da Educação, Campinas, v. 8, n. 3, p. 173-205, set./dez. 2008. 


\section{NOTAS}

1. Até 1910, o Estado contou apenas com a Escola Normal da Capital. Uma experiência paralela de formaçáo aconteceu com a criação de cinco Escolas Complementares que também formavam professores, mas em um curso mais simplificado, com ausência da cadeira de Pedagogia.

2. Sobre a educação do corpo em escolas modelares, consultar: Vago (2002); Góis Júnior \& Batista (2010); Moreno et al. (2012).

3. A ideia de civilidade diz respeito à mudança da estrutura psíquica na vida social (ELIAS, 1994).

Recebido em 24 de abril de 2017.

Aprovado em 12 de setembro de 2017. 